\title{
Plantões Jovens: acolhimento e cuidado por meio da educação entre pares para adolescentes $e$ jovens nos Centros de Testagem e Aconselhamento - CTA '
}

\section{Youths on Duty: reception and care for adolescents and young people at testing and counselling centres '}

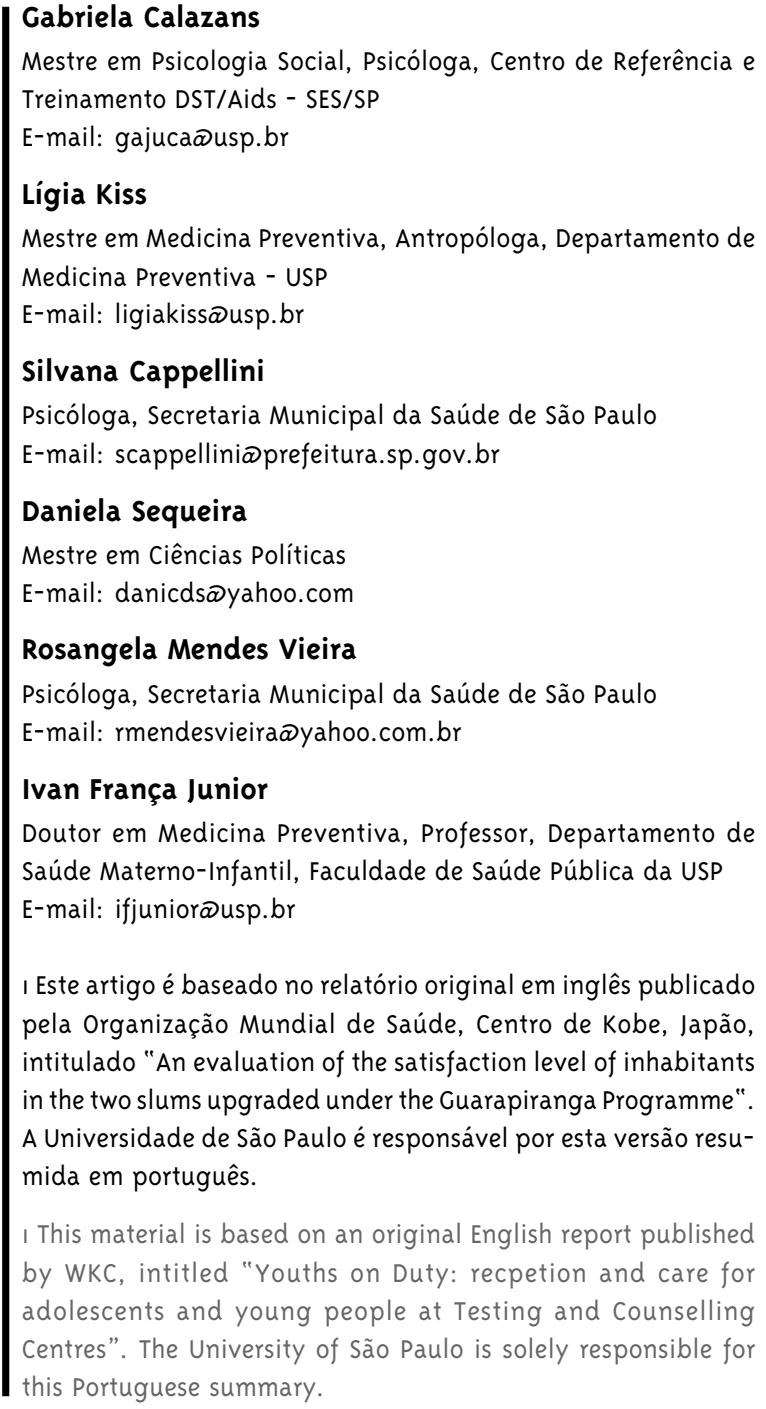

I Este artigo é baseado no relatório original em inglês publicado pela Organização Mundial de Saúde, Centro de Kobe, Japão, intitulado "An evaluation of the satisfaction level of inhabitants in the two slums upgraded under the Guarapiranga Programme". A Universidade de São Paulo é responsável por esta versão resumida em português.

I This material is based on an original English report published by WKC, intitled "Youths on Duty: recpetion and care for adolescents and young people at Testing and Counselling Centres". The University of São Paulo is solely responsible for this Portuguese summary.

\section{Resumo}

O Brasil encontra-se com a maior população jovem de sua história. Há um fator agravante para a difícil situação que enfrentam os jovens brasileiros, pois eles vivem em regiões de maior vulnerabilidade social. Estes jovens têm necessidades específicas e devem ser desenvolvidas políticas públicas que respondam a sua especificidade, dentro de uma perspectiva que encoraje a participação. Uma estratégia inovadora na perspectiva da educação entre pares foi desenvolvida no âmbito dos Centros de Testagem e Aconselhamento (CTA) vinculados à Secretaria Municipal da Saúde de São Paulo, denominada Plantão Jovem (PJ). Os PJ são formados por jovens entre 16 e 24 anos, que atuam junto a seus pares em ações de acolhimento, aconselhamento, oferta de insumos e de palestras educativas. Este artigo descreve os PJ, na perspectiva de seus jovens agentes, buscando compreender como estes compreendem o seu trabalho de educação entre pares. Foram desenvolvidos 3 grupos focais com os plantonistas de quatro CTA implantados em regiões periféricas e de alta exclusão social. Os discursos dos plantonistas valorizam a identidade com os jovens de sua comunidade no desenvolvimento de ações individuais e coletivas, a ênfase no aprendizado prático, o enfoque no encontro e no entendimento do outro. Foram identificados alguns pontos de tensão no desenvolvimento da proposta: valorização da informação técnico-científica X centralidade do encontro e do diálogo, no âmbito da prevenção de Aids; confusão entre identidade pessoal e profissional, como paradoxo da educação entre pares; confusão entre agentes e técnica operacionalizada no contexto da educação entre pares. 
Palavras-chave: Educação entre pares; Juventude; Adolescência; Prevenção; Aids.

\section{Abstract}

Brazil is facing its major youth population of its history. There is an aggravation for the difficult situation met by young Brazilians nowadays, because they live in regions submitted to great social vulnerability. Young people have specific needs and public policies must be addressed to their particularity, within a participation perspective. An innovative strategy of peer education was developed within the Volunteer and Counseling Testing Clinics (VCT) from the Secretaria Municipal da Saúde de São Paulo, intitled Plantão Jovem (PJ). The PJ is integrated by 16 to 24 years old youth that develop welcoming and counseling activities, condom distribution and educative lectures. This article describes the PJ from their young agents perspective, aiming to understand how they comprehend their peer-work. Three focal groups were developed with the peer-workers from four VCT clinics from the peripheric and highly social excluded regions. The peers-workers speeches value the identity shared with their communities' youth in the development of individual and group activities, the emphasis in the practical learning, the focus on the encounter and the other understanding. There were identified some critical points in the development of the proposal: value of techno-scientific information versus the encounter and dialogue centrality within Aids prevention; confusion among personal and professional identities, as a peer-education paradox and the confusion between agents and operational technique within peereducation.

Key-words: Peer-education; Youth; Adolescence; Prevention; Aids.

\section{Introdução}

O Brasil está vivendo a chamada "onda jovem", pois a década de 1995 a 2005 comportou a maior participação relativa de adolescentes e jovens no conjunto da população brasileira. Através de uma análise demográfica que enfatiza os processos relativos a grupos etários específicos em contraposição à observação de tendências populacionais gerais, pesquisadores brasileiros têm enfatizado o crescimento da população jovem (15 a 24 anos), em relação às gerações anteriores de jovens (Bercovich e col., 1998). A distribuição dos jovens na cidade de São Paulo se dá de modo desigual e desfavorável, com maior concentração em distritos com as piores condições socioeconômicas (Rodrigues e col. 1998). Em que pese estas dificuldades, os jovens têm recebido poucas iniciativas públicas, em particular no campo da saúde.

Estratégias de desenvolvimento de educação em saúde por meio de educação entre pares têm sido muito divulgadas nos últimos anos (Wren e col., 1997; Walker e Avis, 1999; Milburn e Wilson, 200o). 0 contexto escolar é quase sempre privilegiado no desenvolvimento de ações de prevenção voltadas a jovens, por haver o entendimento de que este seja o espaço de maior freqüência de adolescentes e jovens. Os serviços de saúde, por sua vez, têm mostrado dificuldade de serem organizados para atenderem adolescentes e jovens.

Apesar do apelo com relação à participação juvenil, a adoção da estratégia de educação entre pares tem sido feita por projetos originados nas distintas abordagens de prevenção de Aids entre jovens identificadas por Ayres e col. (2003). A primeira vertente centra-se na transmissão da informação e visa basicamente modelar comportamentos de risco com base no comportamentalismo. A segunda vertente, menos predominante e mais recente que a primeira, enfoca aspectos culturais, econômicos, políticos e morais que condicionam os comportamentos de risco com vistas a produzir uma resposta social capaz de transformar os contextos que favorecem tais comportamentos (Ayres e col., 2003)

Dentre os estudos realizados sobre educação entre pares, a maior parte da literatura é proveniente dos Estados Unidos, dedica-se a avaliações quantitativas sobre a eficácia dos programas e pouco atenta para aspectos do processo (Milburn e Wilson, 200o). Al- 
guns estudos se referem à experiência dos educadores de pares, mas também na ótica da comparação e da avaliação da efetividade dos programas de prevenção (Ebreo e col., 2002; Ayres e col., 2003).

Em 2003, foi implantada uma iniciativa de educação entre pares, voltada a adolescentes e jovens, no âmbito dos Centros de Testagem e Aconselhamento (CTA) da Secretaria Municipal de Saúde de São Paulo, intitulada Plantão Jovem. Os CTA, como serviços de saúde predominantemente diagnósticos e preventivos, mostram-se provavelmente mais adequados à lógica da promoção da saúde e à aproximação com a população juvenil.

O trabalho de aconselhamento nos Centros de Testagem e Aconselhamento Sorológico (CTA) prevê que: (...) os usuários são estimulados pela via do trabalho de educação em saúde, a adotar comportamentos $e$ práticas mais seguras no que diz respeito à infecção pelo HIV e outras Doenças Sexualmente Transmissiveis, independentemente do resultado do exame.

$\mathrm{O}$ aconselhamento é definido como um processo de escuta ativa, centrado no contato direto com o cidadão. Pressupõe a capacidade de estabelecer uma relação de confiança entre os interlocutores, visando o resgate dos recursos internos do cidadão para que ele mesmo tenha possibilidade de reconhecer-se como sujeito de sua própria saúde e transformação. Tratase de uma prática que visa mudança de comportamento de risco e, ao mesmo tempo, apoio emocional para manejo eficaz da situação de comunicação do diagnóstico, através da consistência, uniformidade e precisão das informações prestadas (extraído de Diretrizes dos Centros de Testagem e Aconselhamento - 2003).

Esta pesquisa foi realizada com financiamento do Programa Cidades e Saúde, iniciativa do Centro de Desenvolvimento da Saúde da Organização Mundial de Saúde (OMS) em Kobe. Este projeto visa integrar gestores de políticas públicas municipais, universidades e a OMS, com vistas a promover maior conhecimento sobre políticas públicas municipais de saúde, para o seu aprimoramento e sua divulgação num banco de dados gerido pelo Centro OMS/Kobe.

Este artigo descreve os Plantões Jovens, uma experiência de educação por pares em prevenção de DST/ Aids, na perspectiva de seus jovens agentes, buscando compreender como estes jovens agentes de prevenção entendem o seu trabalho de educação entre pares.

\section{Metodologia}

O Plantão Jovem (PJ) é uma estratégia de educação entre pares, articulada à prestação de serviços, dirigida a adolescentes e jovens em serviços de saúde especializados em doenças sexualmente transmissíveis e Aids (DST/Aids) vinculados à Secretaria Municipal de Saúde de São Paulo, por meio de proposta da Área Temática de DST/Aids. Tal estratégia foi implantada no ano de 2003, inicialmente num Centro de Testagem e Aconselhamento (CTA) na Zona Leste da cidade, a partir do diálogo com um grupo juvenil local. Posteriormente, a mesma estratégia foi estendida a outros CTA, além de Serviços da Atenção Especializada (SAE), CPA (Centro de Prevenção e Assistência) e Centros de Referência (CR).

Os PJ têm uma equipe de quatro jovens plantonistas, com idades entre 16 e 24 anos, que atuam sob a supervisão de um profissional de nível superior do serviço. Os jovens plantonistas prestam serviço voluntário e recebem uma ajuda de custo no valor de R\$ 300,oo. Há um compromisso informal de que os jovens devem ter uma dedicação mínima de 20 horas semanais às atividades do PJ. Um jovem pode atuar no PJ até que complete 24 anos de idade, não havendo tempo máximo de atuação que não seja este.

A proposta da Área Temática de DST/Aids, de acordo com relatos da coordenação à época, buscou atender a princípios de defesa dos direitos civis e humanos, respeito à diversidade e construção da cidadania, estabelecendo uma comunicação mais efetiva que atenda às necessidades específicas de cada uma das populações às quais se dirigem os esforços de prevenção (Mesquita, 2003). Sendo assim, na proposta dos Plantões Jovens, os jovens plantonistas recebem como atribuições o desenvolvimento de atividades externas e internas aos serviços de saúde em que são alocados buscando sempre efetivar o diálogo com jovens das comunidades atendidas. As atividades externas se dirigem à identificação de locais freqüentados por jovens, na região de abrangência dos serviços, à realização de atividades de conscientização quanto à prevenção das DST/Aids, o que pode ocorrer por meio de ações individuais e coletivas, bem como à oferta de testagem sorológica e de insumos para a prevenção. No âmbito dos serviços de saúde em que estão alocados, os jovens plantonistas são responsáveis pelo acolhimento, 
aconselhamento e oferta dos insumos aos jovens usuários do serviço.

No momento do estudo, o PJ estava implantado em 14 serviços, sendo 7 CTA, 4 SAE, 2 CR e 1 CPA (Centro de Prevenção e Assistência). Nesta pesquisa, optouse por estudar os Plantões Jovens desenvolvidos no âmbito dos CTA pelo reconhecimento, por parte da Área Técnica de DST/Aids da Secretaria Municipal da Saúde, quanto "à perspectiva inovadora na direção de acolher e atender com qualidade o jovem, na ótica do atendimento por pares, em desenvolvimento nestes serviços” (Mendes Vieira, 2004).

Foram incluídos neste estudo os plantonistas de quatro CTA, por estes terem equipes de plantonistas completas e apresentarem diversidade em relação às formas de implantação do serviço e de seleção destas equipes e de características da região onde estão inseridos. Todos os CTA estudados estão situados em regiões periféricas do município de São Paulo.

O CTA Leste 1 foi o primeiro a ter o PJ implantado em fevereiro de 2003 após discussões com um grupo de jovens que já atuava na região militando, principalmente, nas questões de direitos, exclusão social e racismo. Este CTA está localizado na zona leste da cidade de São Paulo, no território da Subprefeitura de Cidade Tiradentes, que corresponde ao do distrito administrativo de mesmo nome com uma população de 59.615 adolescentes e jovens entre 10 a 24 anos, que representam 31,3\% do total da população neste território (PMSP, 2006). Ao longo do ano de 2003, o PJ foi implantado nos demais CTA em estudo. O CTA Leste 2 atende, potencialmente, a uma população de 113.874 adolescentes e jovens, que representam 30,1\% da população da subprefeitura de São Miguel, que abrange os distritos administrativos de São Miguel, Jardim Helena e Vila Jacuí (PMSP, 2006). O CTA Leste 3 atua numa região com população estimada de 110.070 adolescentes e jovens, entre 10 e 24 anos, que representam 30,6\% da população atendida pela subprefeitura do Itaim Paulista, que engloba os distritos administrativos do Itaim Paulista e Vila Curuçá (PMSP, 2006). O CTA Sul está implantado numa região em que residem aproximadamente 148.165 adolescentes e jovens entre 10 e 24 anos, representando 30,6\% da população residente no território atendido pela subprefeitura do Campo Limpo, que abrange os distritos administrativos do Campo Limpo, do Capão Redondo e da Vila Andrade (PMSP, 2006).

\section{Coleta e análise de dados}

Procedeu-se a coleta de dados por meio de grupos focais. Foi realizado um grupo focal em cada serviço eleito, sendo que por questões operacionais, os plantonistas dos CTA Leste 2 e 3 foram reunidos no CTA Leste 2. Os grupos focais foram realizados com 10 participantes no CTA Leste 1, sete plantonistas no CTA Leste 2, sendo três deste mesmo serviço e quatro provenientes do CTA Leste 3, e quatro plantonistas no CTA Sul 1. Estes grupos foram desenvolvidos por um moderador e um observador.

0 roteiro desenvolvido para condução destes grupos visava conhecer como os plantonistas vivem seu processo de trabalho no atendimento a seus pares, destacando o início da participação no PJ e sua motivação, o treinamento recebido para o desempenho de sua função e a relação com o supervisor de seu trabalho e com o restante da equipe, bem como aspectos positivos e dificuldades experimentadas no trabalho e na relação com o adolescente/jovem usuário.

Os encontros foram gravados e o material coletado foi posteriormente organizado de acordo com as categorias analíticas da teoria do trabalho em saúde, tais como saber operante, características da equipe, finalidade do trabalho entre outras (Mendes-Gonçalves, 1979, Schraiber, 1999). Utilizamos técnicas de análise de conteúdo como um segundo procedimento de coleta de dados (Bardin, 1977; Minayo, 200o). A análise de conteúdo consiste em um conjunto de procedimentos que se propõe a descrever aspectos das formas simbólicas, objetiva e sistematicamente, por meio de categorizações. As categorias de análise foram definidas dedutivamente, a partir dos objetivos do estudo, do próprio material a ser analisado e da teoria do trabalho (Pope, 2005). Esse procedimento visou a desvelar sentidos implícitos nas falas dos jovens plantonistas, destacando aspectos subjacentes, de acordo com os objetivos do estudo.

\section{Aspectos éticos}

A realização deste estudo se deu em conformidade às orientações da Resolução nº196/96 do Conselho Nacional de Saúde, tendo sido analisado e aprovado pelo Comitê de Ética em Pesquisa da Secretaria Municipal da Saúde de São Paulo. Os jovens plantonistas dos CTA pesquisados foram informados sobre o caráter confidencial de sua participação e sobre o objetivo da 
pesquisa e assinaram o Termo de Consentimento Livre e Esclarecido.

\section{Resultados}

\section{Recrutamento e seleção dos plantonistas}

Os discursos dos jovens plantonistas informam que a implantação do PJ nos diferentes serviços teve importantes diferenças no que tange a forma de recrutamento e seleção dos jovens plantonistas. No CTA Leste 1, os plantonistas compreendem que a sua seleção esteve condicionada a sua participação no grupo juvenil autor da proposição original do Plantão Jovem, aqui nomeado “Grupo Jovem”, que já desenvolvia ações de prevenção em DST/Aids em sua comunidade. Segundo os jovens plantonistas do CTA Leste 2, neste serviço

\section{Quadro I - Recrutamento e seleção dos plantonistas}

\section{CTA LESTE ।}

"É tipo assim, como eu faço parte do Grupo Jovem, então eu fui escolhido para estar também iniciando um trabalho aqui no CTA, entendeu? Então praticamente quem colocou aqui no CTA foi o grupo, entendeu? Eles fizeram uma seleção de quatro jovens para estar fazendo um trabalho aqui de prevenção no CTA e eu fui um dos escolhidos para estar trabalhando".

"Eu conheci o Grupo Jovem através da biblioteca comunitária, eu estava procurando um livro pra ler, então eu conheci as pessoas que estavam lá, então eu conheci e aí as pessoas de lá me convidaram para eu ir na reunião, eu comecei a participare comecei a entender o que era o Grupo Jovem, o que era a comunidade, aí eu comecei a me engajar nos trabalhos. Virei integrante assim, aí um dia, eu não, eu comecei a fazer parte do Plantão Jovem desde a saída de um dos membros do Grupo Jovem, que eu vim pra cá, e aí a gente está aqui. (...) Então, nós já fazíamos um trabalho antes, então aqui é mais um trabalho, eu já estava participando de encontros, em Guaianazes, participando de outros projetos, então já fazia em outros locais, então eu vim pra cá continuar o trabalho que a gente fazia".

\section{CTA LESTE 2}

Dois dos jovens do CTA Leste 2 pertenciam a um movimento cultural houve duas modalidades de seleção. Dois dos jovens referem ter participado de um treinamento a convite de um grupo cultural do qual faziam parte e os contatos ali estabelecidos possibilitaram sua incorporação ao Plantão Jovem quando o mesmo foi implantado neste CTA. Outro plantonista, no entanto, passou a integrar a equipe por usar o CTA regularmente de forma espontânea depois de que foi informado da existência do serviço por sua irmã. No CTA Leste 3 , os jovens referem que sua seleção pôde ocorrer a partir da indicação dos jovens por profissionais do serviço ou de outras instância da administração pública. No CTA Sul, os jovens identificam como critério de sua seleção seu engajamento anterior a movimentos sociais na região e a experiência anterior com temas relacionadas ao trabalho atual (HIV/Aids). local, o qual os convidou a participar de um curso sobre sexualidade num SAE da zona leste. A partir dos contatos estabelecidos na ocasião, foram selecionados para trabalhar no serviço.

Apenas um dos jovens passou a integrar a equipe por usar o CTA regularmente de forma espontânea.

"Eu nem sabia que existia. Nunca tinha nem ouvido falar. Aí minha irmã veio aqui, negócio de escola também. Ela veio aqui, fez uns exames e foi quando eu conheci o CTA. Saí me falaram que estava tendo uns negócios lá, tipo um treinamento. Faz uns 3 meses já".

\section{CTA LESTE 3}

"Eu fui indicado pela minha avó, que conhecia um pessoal da Coordenadoria. Eles estavam precisando, né? Aí eu fui atrás...". "Eu não sabia que tinha o CTA, que existia o CTA. E eu fui indicada pela Coordenadoria de Saúde, por uma amiga da família".

\section{CTA SUL}

Ao começarem a trabalhar no CTA, a maioria dos plantonistas já vinha de trajetória pessoal de engajamento em movimentos sociais. Trabalhavam anteriormente com temáticas da área e já haviam desenvolvido alguma reflexão quanto à sua comunidade.
Há ainda diferenças quanto à vinculação dos jovens aos grupos que possibilitaram seu contato inicial com o CTA e com a proposta de trabalho do PJ. En- quanto no CTA Leste 1, o vínculo dos jovens com o seu grupo juvenil de origem mantém-se central e mais forte do que com o próprio CTA, nos demais CTA em 
que o recrutamento dos plantonistas se deu por sua participação anterior em algum grupo ou movimento social, este vínculo foi substituído à medida que os jovens passaram a integrar o PJ. Esta diferença marcante se fez presente na realização do grupo focal no CTA Leste 1 em que estiveram presentes e participantes, além dos quatro plantonistas, seis integrantes do grupo juvenil de origem. No discurso de uma jovem plantonista nota-se que a atuação no PJ se faz presente com o mais uma, dentre várias atuações comunitárias do grupo juvenil de origem.

\section{Processo de formação e treinamento}

Os jovens consideram que o aprendizado do trabalho no PJ efetiva-se na prática cotidiana, principalmente a partir da qualidade da relação que constroem com os usuários. 0 aprendizado a que se referem diz respeito não ao conteúdo que devem transmitir, mas à qualidade da relação interpessoal com o usuário. Vêem a interação como o aspecto central do seu trabalho, marcada pela tentativa de compreensão do outro.
Complementarmente, os plantonistas valorizam bastante o investimento em sua formação e o acesso a conhecimentos de base técnico-científica, proporcionado a partir do trabalho no CTA. Julgam a legitimidade de seu trabalho, associada ao reconhecimento pelos pares, pela quantidade e qualidade de informações de que dispõem. Entretanto, a maioria diz não ter tido treinamento formal, aspecto do qual se ressentem, e por valorizarem o domínio da linguagem técnico-científica com que têm contato nas atividades de formação, acreditam que os investimentos em treinamento e capacitação são insuficientes e carecem de estruturação e continuidade.

Em alguns CTA, a atividade de supervisão faz as vezes de treinamento e oferece os esclarecimentos e o suporte necessários para a realização do trabalho, especialmente no que tange à construção do seu saber operante. A importância conferida à supervisão, no entanto, varia entre as equipes de plantonistas dos diferentes CTA.

\section{Quadro 2 - Processo de formação e treinamento}

"Questão do acolhimento, como receber... Assim, mais ou menos, como você tratar a pessoa. Tipo assim: eu aqui, o balcão ali e a pessoa do outro lado. Você tem que ser mais um amigo da pessoa. Mas, assim, não sei se vocês concordam, por mais treinamento que a gente tenha, a gente aprende mesmo é na prática. A gente sabe o quê tem que fazer, mas enquanto não praticar...".

"Recebi vários livros para estudar, revistas... Aprendi como a lidar com o público, assim... Eu de um lado, a pessoa de outro... Melhor, só aprendendo na prática".

"Quando a gente tem alguma pergunta que não sabe responder, a gente fala pro usuário voltar outro dia. Então, a gente se apóia no Posto, no PSF, e a gente também é autodidata, vai lendo, vai se informando e procura a informação. Quando a gente entra em relações de violência de gênero, a gente discute e com o preparo que a gente já tem. E quando a pessoa quer mais e mais, a gente orienta para que procurem livros, biblioteca, e outros espaços que podem colaborar com o assunto."

"É assim: quem tem menos de um ano no CTA não tiveram esses treinamentos que os que têm mais de um ano tiveram. Eu digo isso porque eu tenho quatro meses, né? Então, eu, foi mais assim, eu já tive oportunidade de lidar bastante com pessoas. Já trabalhei em comércio, então eu tenho mais facilidade. Mas, assim, treinamento? Ouvi eles, né? A companheira ajudava, né?
E, assim, sempre corri atrás. Perguntava para nossa treinadora, né? Então, foi mais esforço nosso também. Se a pessoa gostou do trabalho e corre atrás, né? Vai se esforçando. (...) Mas, assim, eu mesmo, foi na prática. Eu comecei, eu não tive, assim, igual ele, uma outra pessoa para estar me apoiando. Foi praticamente sozinha. E eu me virei sozinha. Agora, como ele está entrando, ele é recente.... Eu, no caso, quando eu entrei, eu senti uma falta de apoio porque na tarde eu fico sozinha. Então, para ele não sentir o mesmo, eu estou dando todo o apoio para ele, o quê ele precisar... (...) Então, foi mais na prática mesmo, perguntando para o pessoal mais velho, né?".

"Ah, o treinamento... Nós recebemos pouco para falar a verdade. 0 treinamento foi mais o dia-a-dia com a nossa técnica. Ela sentava aqui, fazia direto... ela estava conversando, passando material para nós estar lendo. Esse foi o treinamento".

"Muito pouco, assim, da Secretaria, muito pouco. Mas, assim a nossa técnica é muito boa, então, assim, ela tira dúvida, dá livros. A gente vai muito a seminários, a cursos, essas coisas, quando a gente tem oportunidade. (...) Mas, assim, treinamento mesmo, aqui dentro, foi mesmo assim, com curso, livros que a I. [supervisora] dá e as supervisões, que não deixam de ser um treinamento porque a gente tira dúvida... Tudo é na supervisão". 


\section{Relação com a equipe do CTA}

O vínculo com as equipes dos CTA se dá quase exclusivamente na figura do supervisor. Nesse sentido, os plantonistas do PJ acabam mantendo um diálogo pontual com os outros membros da equipe. A falta de integração com a equipe faz com que não existam encaminhamentos internos, o que obstrui a trajetória dos usuários entre os diferentes planos da assistência prestada nos CTA. De forma geral, os plantonistas não participam das reuniões gerais de equipe e sentem que o sentido do seu trabalho permanece desvinculado das demais ações da unidade. Na percepção dos plantonistas, as ações do PJ não são incluídas em um projeto comum de trabalho. Queixam-se que seu trabalho precisaria ser mais apoiado e respeitado pelos serviços em que atuam, pois se ressentem da falta de material para ser entregue aos jovens usuários e de retaguarda material para o desenvolvimento das ações. Nos CTA onde a relação com a supervisora é muito próxima e acolhedora, a relação com a equipe também foi relatada como mais confortável, mesmo que tenha sido sentida resistência inicial.

\section{Quadro 3 - Relação com a equipe do CTA}

"A questão de encaminhamento fica prejudicada. A gente fica sem auxílio em casos de abuso sexual, violência doméstica. Falta técnico com o perfil do CTA. Não é só emprego, é uma militância".

"Havia um certo receio da equipe quanto ao trabalho dos jovens. Agora está tudo bem. Antes, todo mês, desde que a gente entrou, desde o começo do ano, todo mês, tinha o acolhimento. E era exatamente para isso, para os funcionários conhecerem o trabalho dos agentes de prevenção. Agora, muda de vento em popa, assim, os funcionários conhecerem o quê a gente faz... Vendo um bando de jovem que estava para lá e para cá, é claro que os funcionários se sentem até meio que ameaçados, não é verdade? 'A gente tá aqui para trabalhar, eles vêm roubar nosso emprego!?' Eles pensam meio que é isso. Dá para ver nos olhos".

\section{Ações desenvolvidas (individuais e coletivas)}

Um aspecto valorizado no desenvolvimento das ações dos jovens plantonistas é atribuído por eles ao compartilhamento de linguagens e experiências, por terem a mesma idade que os usuários e viverem no mesmo bairro ou contexto social. Este compartilhamento é percebido como um elemento fundamental ao estabelecimento de uma relação fundada no diálogo. Procuram, nesse sentido, manter-se atualizados em relação aos focos de interesse e atividades cotidianas dos usuários para dispor de um repertório comum e favorecer a comunicação e a relação interpessoal com eles. Acreditam, porém, que nem todos os usuários buscam esse tipo identidade etária em um serviço como o CTA. Há a compreensão de que os usuários possuem motivações e necessidades distintas.

Dentro do serviço, as ações do PJ são de dois tipos: orientações individuais e em grupos. A primeira modalidade distingue-se pela ênfase na escuta e no diálogo, em que a construção de vínculo de confiança com o usuário é um aspecto central do atendimento. Vêem a interação como parte importante do seu trabalho, marcada pela tentativa de compreensão do outro e de valorização da diversidade que percebem nos sujeitos que atendem. No atendimento individual afirmam não seguir um roteiro prévio de atendimento.

A realização de atividades coletivas pode ocorrer dentro e fora dos serviços. As atividades programadas fora do serviço consistem basicamente de palestras em escolas e distribuição de materiais educativos entre jovens, nos ambientes sociais em que convivem. Na realização de atividades coletivas, contrapõem sua capacidade de abrir o diálogo, às atividades de educação em saúde tradicionais, desenvolvidas por técnicos e adultos, tais como palestras. Identificam, nestas atividades tradicionais, a fala do técnico que não se mostra disponível a ouvir os usuários, motivado, segundo os jovens, pela compreensão de que a população usuária não dispõe de informações relevantes sobre prevenção.

Na realização destas atividades coletivas, os plantonistas referem usar fotos e relatos de doenças e suas manifestações, com o objetivo de que os jovens sintam-se ameaçados pela possibilidade de contraílas e, com isso vejam-se estimulados a fazer uso do preservativo. Nos grupos ainda, os jovens plantonistas recorrem à linguagem técnico-científica a que tem acesso nas atividades de formação e supervisão, com a intenção de homogeneizar e disciplinar os termos das falas dos usuários. Buscam, assim, derrubar preconceitos e imprimir naturalidade aos discursos do grupo sobre assuntos tidos como "tabu" entre jovens como, por exemplo, a nomeação dos órgãos sexuais e modalidades de práticas sexuais. 
Os plantonistas manifestam identificar uma desconfiança inicial quanto ao seu trabalho, pois seriam julgados inexperientes e despreparados pelo fato de serem jovens. Declaram que o reconhecimento vem com o desenvolvimento do seu trabalho, a partir do momento em que demonstram a competência adquirida. Isto ocorre tanto nos grupos que realizam nos serviços, quantos nas atividades em escolas, onde a desconfiança vem dos diretores e professores.

\section{Quadro 4 - Ações desenvolvidas (individuais e coletivas)}

\section{"A linguagem é a mesma".}

"E, assim, a gente procura também estar sempre se informando na televisão. A gente procura ver o que está acontecendo... Novela".

"... na Internet. Toda sexta-feira a gente sobe no Telecentro para estar vendo o quê que tem de novo na Internet, para estar acessando. E vendo a televisão para ver o quê está acontecendo porque adolescente assiste muita televisão. Então, de repente, se a gente vê alguma coisa lá, não entende direito, pergunta para a l...".

"A gente usa jornal. A gente até fez umas colagens. A gente pegou a caixa da camisinha, colou. No jornal vem aquelas dúvidas de adolescente. A gente cola para a gente sempre ter isso também. Então a gente sempre está procurando, de tudo que é forma, se atualizar..."

"A nossa linguagem é muito importante porque se identifica, né? Porque, por exemplo, eu vou bastante para 'salão', então aquele adolescente (...), eu consigo saber as gírias deles. Às vezes, a gente fala assim: 'Existe sexo oral, anal e vaginal'. Eles não sabem. Então eu já vou diretamente: 'É um pênis'. Aí: 'Você sabe o quê é um pênis?' Eu vou na brincadeira. Vou levando ele: 'Nossa é diferente'. Porque quando a gente vai pra fazer uma oficina a gente não vai só falar e eles escutar. Eles também vão falar. Então isso muda o quadro porque eles vão agir com a gente, vão... assim eles vão conseguir refletir. Quebra aquela coisa: 'Ah, mas eu já sei tudo isso'. Pra gente é diferente porque a gente trabalha com dinâmica e eles se animam mais para estar participando dos encontros".

"Tem jovem que ele prefere ser atendido por aconselhador enquanto têm outros que: 'Não, eu quero falar com alguém da minha idade, tal'. Então, é bem.... É bem equilibrado, eu acho, assim. Não é a grande maioria que... só porque é jovem quer falar com jovem. Tem uma menina que ela se sente melhor com uma pessoa adulta porque ela acha que eu vou levar o papo dela, né, no igual, assim e não vou entender ela. E tem menina que não tem relacionamento bom com a família, com a mãe, por exemplo, aí ela vê a aconselhadora como uma figura de mãe para ela. Aí eu seria, então, uma figura de amiga. E amiga ela já tem. Então é mais ou menos isso. Isso acontece bastante, bastante mesmo. Então os jovens são bem diversos mesmo".
"Assim, pessoalmente, é muito bom porque, assim, receber palestra de sexualidade com 'tiozinho' é fogo. 'Tiozinho' é fogo, falando lá dos negócios é complicado. Mesmo por causa da linguagem. Ele fala tanta coisa que a gente muitas vezes não entende, não por falta de comunicação, mas pelas experiências da vida, mesmo. Então o contato do jovem com jovem facilita muito a gente estar conversando e eles aprendem até mais mesmo do que, tal, colocar um senhor lá... porque é uma coisa nova, né? Jovem com jovem. A gente também usa dinâmicas para facilitar esse contato, né, quebrar o gelo que eles têm. Então, é muito bom".

"Hoje já diminuiu bastante o preconceito. Mas a gente sempre encontra algumas barreiras. Você vai trabalhando $e$ conquistando o respeito das pessoas. Você consegue levar o trabalho de saúde para as pessoas. As pessoas estão mudando essa concepção. Esse espaço para o adolescente falar de saúde ajuda elas a perceberem que o CTA se interessa por elas, que tem espaço".

"No começo, eles olham: 'Nossa, são vocês que vão dar a palestra?' Aí aquela coisa: não acreditam muito no que a gente é capaz de fazer. Mas, aí, durante a palestra, eles vão...".

"O pessoal tem preconceito. Olha para a gente, cara novinho, tal...".

"De primeira tem uma barreira, assim: 'Cadê o auxiliar de enfermagem? Cadê?"”.

"Eles exigem, assim, um profissional, um enfermeiro ou um médico. É igual uma palestra que foi marcado, a gente recebeu um ofício, aí a professora daquela escola: 'Ah, é médico que vai?' E era para adolescente, né? E quem faz a parte de adolescentes somos nós. Então a gente tem aquele preconceito, né? As pessoas não valorizam nosso trabalho. A gente gostaria que as pessoas valorizassem mais, né?".

"Acho que nem é por não valorizar. Acho que é por falta de conhecimento às vezes, né? Já aconteceu, assim, de a gente dar a palestra e a professora ficar meio com medo, na escola, por exemplo. Depois que termina essa palestra, faz bastante brincadeira, faz a dinâmica, o professor já muda a cara. Ele já quer que você vá para outra sala, já fala para outro professor. Então, assim, a gente mostra o contrário, né? Mas o mais difícil é a gente poder ganhar esse espaço, ter essa confiança, né?". 


\section{Impacto do trabalho sobre a imagem dos jovens plantonistas}

Tornar-se referência entre os jovens de sua comunidade para esclarecimentos sobre prevenção das DST e da Aids e fornecimento de preservativo, por um lado, torna-os conhecidos e valorizados no grupo, porém, por outro, abre caminho para dois tipos de impactos em suas vidas considerados negativos. Em primeiro lugar, possibilita a invasão do seu espaço doméstico, reservado para suas vidas pessoais e familiares, por jovens buscando preservativos a qualquer momento. Em segundo lugar, referem sentir que, em função da exposição experimentada nesta função de plantonista jovem, ficam sujeitos ao julgamento dos seus pares nos espaços de socialização juvenil da comunidade.

\section{Quadro 5 - Impacto do trabalho sobre a imagem dos jovens plantonistas}

"Lá perto onde a gente mora, a gente é conhecido como os menino da camisinha amarela. É divertido".

"Os amigos gostaram, né, porque agora camisinha é o quê não falta para eles. Já foram de madrugada lá bater na porta pedindo camisinha".

"Quando você tá sozinha, as pessoas meio que confundem, as coisas, sabe? Não sei se é porque você trabalha no serviço, tal... Então: 'Essa daí, vamos lá, que... rola qualquer hora'. E não é bem assim. Porque as pessoas acham: 'Ela é expert em sexo'. Não é assim, sabe? Então, às vezes, rola assim, tem umas pessoas que pegam um pouco pesado".

"Os amigos, eles ficam assim agora: 'Agora a gente tem uma sexóloga. Ela era safadinha, agora ela vai ficar mais safadinha'. Eles ficam achando que por a gente... Acho que a gente tem até mais vergonha porque... sei lá... Eles meio que deixam a gente com vergonha porque eles acham que a gente sabe tudo, que a gente sabe fazer tudo, que a gente vai ensinar todas as posições: 'Não, mas qual é a posição melhor aí? Qual é a posição que você faz?'”.

"E a gente vira meio que consultora, assim. Se eles vão pegar uma menina, os meninos, eles vêm na gente: 'Não, e aí? 0 que a gente tem que fazer? o quê que... não sei o quê...' Aí eu: 'Gente, eu não sou professora de sexo, não, sabe? Pega leve!'”.

"Todo mundo fica perguntando. Vão em casa, assim, te perguntar sobre orgasmo, essas coisas. Então a gente pega uma identificação. Porque, quando eles chegam na minha casa: 'Ah, você é professora de sexo'. Aí teve um caso que eu tava com meu namorado, chegou dois meninos que eu tinha feito oficina, falou assim... Eu fiz com um e não fiz com o outro. Aí ele chegou e falou assim: 'Olha a minha professora de sexo'. Aí o menino falou: 'Mas você dá aula de sexo?' Eu falei: 'Não, não é isso'. Aí o outro falou assim: 'Ah, mas será que é isso?' Aí eu fui conversar com ele para falar que não era aquilo, que eu não era professora de sexo. Porque eles pensam que a gente pratica, né, que é uma coisa que a gente vai explicar como é que vai fazer posição, essas coisas. Aí, quando a gente fica conversando, a gente vê que não é nada daquilo. Mas tem gente que toma como referência. Porque, na minha casa, todo lugar que eu vejo, tem camisinha. Tem hora que eu fico até meio sufocada, né?".

"A gente não pode fazer muitas coisas com a Igreja. Tem sempre um limite para a gente estar fazendo as coisas na Igreja. Quando a gente vai, acessar campo, falar tudo, a gente tem sempre uma barreira".

"Minha mãe é um caso à parte. A minha mãe era evangélica, assim, então ela detestou, assim. Se ela pudesse... porque ela já não gostava muito da associação, que era bem dinâmica, né? Então, quando a associação começou a fazer serviço voluntário de (...) de prevenção, ela já não gostou. Aí eu vejo um lugar para trabalhar com isso... Ela achou o cúmulo! Porque a Igreja dela prega que você tem que casar virgem, tal, e eu distribuo camisinha para as pessoas fazer sexo. Então, ela quase morre! Então, ela odeia. Mas, assim, com o passar do tempo, ela viu que isso é só meu serviço. E que é melhor eles usarem camisinha do que não usarem e vão fazer de qualquer jeito, mesmo com camisinha ou não. Então ela meio que colocou isso na cabeça dela. Sobre os projetos daqui, eu nem comento com ela porque se eu comentar, ela me tira daqui. Isso é sério. Ela é evangélica e ela faz uns auê ai par mim... (...) Minha irmã, ela também adorou. Ela é usuária daqui também".

"Bom, lá em casa ficaram feliz porque é um trabalho. Mas, no começo foi meio que preconceituoso por causa do trabalho com AIDS, DST... Você vai dar palestra, tal, né? Mas, eh, tiveram que aceitar porque é um trabalho, né? Com o tempo, foram descobrindo a importância, né? Meus amigos: 'Nossa, você trabalha no CTA?'; 'Nossa, você trabalha...'; 'Você trabalha...'. Sempre perguntam, tal. Qualquer coisa, uma dúvida, sempre vêm perguntar para mim". 
Os plantonistas identificam na imagem dos pares sobre si a construção de uma imagem estigmatizada de si, do trabalho que realizam e do saber de que dispõem para isso. 0 trabalho envolvendo as temáticas da prevenção de aids e de outras doenças de transmissão sexual é referido nesta imagem à promiscuidade sexual, experiência sexual pessoal ou, pelo menos, um maior conhecimento sobre sexualidade e relações de conquista sexual. Os jovens plantonistas referem a existência de ironias e má compreensão quanto ao seu papel pelos pares em algumas situações.

Devido ao objeto de trabalho do PJ, expressam entrar, muitas vezes, em conflito direto com valores mais tradicionais, instituídos no seio da família, religião e outros espaços comunitários, o que afeta a forma como o seu trabalho é percebido pela sua própria família e outros círculos sociais comunitários de sua intimidade. No entanto, apesar de perceberem esta resistência de suas famílias, os jovens referem que há aceitação de sua atividade pela existência de remuneração e pela valorização atribuída pelas famílias à esfera do trabalho.

\section{Finalidades do trabalho}

Para os jovens plantonistas um dos sentidos para o papel de multiplicador que exercem é dado pela construção de uma imagem positiva para servir como modelo para jovens de sua comunidade, o que implica na fuga do estereótipo do adolescente da periferia, vinculado ao uso de drogas e à criminalidade. Neste sentido, acreditam que como multiplicadores influenciam no comportamento dos demais jovens por tornarem-se referência para seus pares.

Os aspectos negativos sobre a sua imagem, referidos anteriormente, são também relativizados frente ao compromisso que afirmam com a finalidade do seu trabalho. Encontram nessa situação de, em certa medida, se tornarem figuras públicas em seu meio social alguma motivação, pois enxergam na publicidade de seu trabalho os resultados das atividades educativas que promovem. Entendem que se são conhecidos e procurados pelos jovens é porque a finalidade do seu trabalho, a educação em saúde para a prevenção das DST/Aids, está sendo atingida.

Mais centralmente, no entanto, os jovens interpretam a finalidade de seu trabalho no PJ como marcada pela mobilização e capacidade de transformação de valores culturais tradicionais relativos ao exercício da sexualidade. Sentem-se mobilizados pelos questionamentos em relação a comportamentos reprodutores das iniqüidades de gênero, percebendo a si mesmos como agentes de mudanças, com possibilidades de disseminar transformações na esfera da moral. É por isso que o trabalho do PJ não se limita às discussões sobre DST e AIDS, mas envolve dimensões da vida cotidiana que causam nos jovens dúvidas e conflitos de natureza subjetiva e mesmo existenciais. Dessa forma, relações familiares, afetivas e sexuais ocupam lugar de destaque como objeto de fala e produção conjunta de sentido, abrindo espaço para que o aprendizado relativo ao corpo, ao prazer e às relações afetivas façam também parte da demanda dos usuários.

Apesar desse projeto mais ambicioso de transformação nos valores tradicionais, acreditam que o preservativo ainda conserve centralidade, entre os pares, no reconhecimento do trabalho que realizam. Na percepção dos plantonistas, sua função no cotidiano de trabalho não se resume à ampliação do acesso ao preservativo, mas este funciona como forma de abordagem e "sinalizador" para o trabalho que realizam. São muitas vezes conhecidos apenas pelas "camisinhas" que levam consigo, porém, vislumbram aí espaço para introduzir na abordagem dos jovens, temáticas da prevenção e educação em saúde.

Defendem, ainda, a idéia de que caberia ao CTA a distribuição de outros meios de contracepção para ampliar os cuidados com os jovens. 


\section{Quadro 6 - Finalidades do trabalho}

"E o bom é que nós somos da comunidade porque eles achavam que, por a gente estar nesse projeto, a gente vinha, assim, de famílias mais ricas e com mais poder e tal. E a gente se identifica porque ele fala assim: 'Poxa, mas se você morou no mesmo bairro que eu, estuda na mesma escola, você conseguiu se identificar... Você conseguiu não ir roubar, não ir usar droga, por que eu não posso?' Porque, quando fala do adolescente de periferia, é como se ele só fumasse, se ele só matasse. Então é uma referência que ele pode estar levando para ele, que ele pode estar fazendo algo, que não seja só isso".

"Porque, assim, os adolescentes, eles se espelham mais numa pessoa que eles vêem, assim. Então, que nem, eles estão na rua, eles vêem um usuário de droga, um ladrão, um traficante, eles falam: 'Não, quando eu crescer, eu quero ser isso'. Aí, eles vindo aqui, eles vão ver que é completamente diferente, que é a mesma idade do que eles e que tá fazendo um serviço diferente. Então, eles vai se espelhar... vai tentar se espelhar em você. Porque já aconteceu isso comigo, de eu estar aqui com uns adolescentes e eles tentar fazer o quê eu tô fazendo. 0 quê eu fazia aqui, eles tavam fazendo. Se eu tava desenhando, eles pegavam, falavam: 'Dá uma folha ai que eu vou desenhar também'. Eu fazia um desenho assim, eles tentavam imitar o meu desenho. 0 quê eu tava fazendo aqui, eles tentavam fazendo. Então eles vêm aqui mais para tentar espelhar você, pra ver de acordo com que você faz. (...). Esse também é um serviço bom por causa disso. (...) Você vê que o adolescente tenta espelhar em você".

"É assim, num grupo, dependendo da área que a gente for trabalhar, a mentalidade é a seguinte: pelo aspecto que ele vive é muito diferente de outros. Então às vezes a gente tem um pouquinho mais dificuldade na questão de conversar determinados assuntos. Por que? Porque a criação daquela pessoa, a realidade dela é completamente diferente de uma outra que a gente foi trabalhar. Então, assim, é um processo que fica um pouco mais lento mesmo. 0 caminho não é o mesmo. Então, às vezes, desconstruir algumas coisas que já tá ali na cabeça daquela pessoa há tantos anos é mais difícil. Por exemplo, tem mãe que cria sua filha, falando assim: 'Ah, minha filha, tem que falar amém pra tudo que seu noivo ou se marido faz, né, ou então tudo que ele fala'; 'Ah, minha filha, homem é assim mesmo, eles traem você mesmo. E você tem que aceitar'. Então, às vezes você mudar alguma coisa, você tentar fazer... E você vê que aquela menina tá se acabando por causa de algumas coisas. Então você tentar fazer a pessoa mudar também o pensamento, assim, abrir os olhos daquela pessoa é um pouco difícil assim"

"Mudar os valores é muito difícil"

"Alguns adolescentes vêm aqui só para desabafar porque a nossa realidade está dada: Cidade Tiradentes. As pessoas estão muito fragilizadas. Como aqui tem uma ausência de políticas públicas para a juventude, às vezes elas vêm aqui mesmo só para desabafar. Elas sabem que aqui tem um espaço no qual elas podem falar".

"Muita gente procura a gente só pra falar. A gente constrói um vínculo de confiança e respeito. A gente tenta procurar parcerias para conseguir trabalhar com esses casos mais dificeis... mas a gente sabe que... a palavra certa (para o tipo de apoio que recebemos) é capenga, né? É complicado, né?".

"Pra mim é assim: o adolescente, quando ele chega aqui, ele só quer falar sobre preservativo, a quantidade de preservativo. Depois que a gente começa a conversa com ele, a gente cria um vínculo. Então, às vezes, ele vem aqui só para bater um papo, para conversar, para falar o quê tá acontecendo com ele. Isso porque a gente se torna amigo dele. Então isso é muito legal. Quando você passa na rua ou quando eu tô na minha escola, que tem adolescente que eles vieram aqui, ai eles falam comigo: 'Ah, eu vou tá lá tal dia, eu gostaria, tal... ' Então você fica feliz por você ver que deu resultado o quê você falou. Quando fala assim: "Ah, mas o adolescente é "aborrecente". Mas não é a realidade. É só dar o espaço dele para ele falar porque, se só você fala, ele não vai mostrar suas qualidades".

"As pessoas perguntam se não tem outros métodos de contracepção. Os adolescentes perguntam por isso. Acho que seria legal oferecer anticoncepcional. (...) As pessoas acham o serviço aqui menos burocratizado". 


\section{Discussão}

O estudo do PJ na perspectiva de seus jovens agentes de prevenção contribuiu de forma significativa para compreender as possibilidades abertas pela relação interpessoal entre os pares para educação em saúde.

As experiências de PJ nos serviços pesquisados são representativas do universo estudado. Este estudo poderia em muito ser acrescido se pudesse ter incorporado outras vozes na construção deste quadro sobre os PJ: os jovens usuários e os técnicos. No âmbito desta pesquisa, buscou-se a realização de grupos com usuários, mas houve pequeno comparecimento de usuários, o que dificultou a análise conjunta dos dados. A observação das atividades desenvolvidas também seria um elemento que enriqueceria bastante a compreensão sobre a oferta de acolhimento e cuidado para adolescentes e jovens.

\section{Recrutamento e seleção dos plantonistas}

Um aspecto central nas estratégias de educação entre pares (Shiner, 1999) é a explicitação sobre as condições de paridade utilizadas por cada projeto e que definem os critérios de recrutamento e seleção dos agentes. As condições que puderam ser observadas em todos os CTA estudados referem-se à idade dos jovens e ao fato de residirem na mesma região de cidade (comunidade). Em alguns CTA, no entanto, houve a avaliação de que a participação ou militância anterior num grupo juvenil pudesse contribuir com a função de educador de pares. Observa-se, entretanto na experiência do PJ, que a paridade é reforçada na formação e no próprio cotidiano de trabalho. Na perspectiva dos jovens agentes de prevenção, a facilidade de comunicação com os jovens se dá por freqüentarem os mesmos espaços na comunidade e possuírem linguagem comum (pela própria identidade geracional e convivência no espaço público, principalmente escola). Por outro lado, a legitimidade que lhes é conferida como educadores, viria do domínio do repertório técnicocientífico transmitido na formação e pela possibilidade de proporcionarem acesso aos preservativos.

\section{Processo de formação e treinamento}

Identifica-se, nas falas dos plantonistas, dois tipos de saber adquiridos no trabalho: 1) o saber prático, acumulado a partir das relações interpessoais com os usuários e que informa métodos e técnicas de aborda- gem e; 2) o saber de base técnico-científica que fundamenta o discurso da prevenção a ser reproduzido nas atividades de educação em saúde.

Tendo como núcleo de seu trabalho o saber prático, (re)produzido a partir das relações interpessoais com os outros jovens, o agente jovem torna-se o principal instrumento da técnica que atualiza (Schraiber, 1997). Os sujeitos e a tecnologia operacionalizada confundem-se na dimensão de sua prática assistencial, já que vêem como competência estrutural do seu trabalho a capacidade de interação e comunicação com seus pares. Está presente neste modelo uma tendência apontada por Shiner (1999) de que os projetos de educação entre pares oscilam entre um foco no desenvolvimento dos educadores-pares ou no de sessões formais de educação. A experiência dos jovens plantonistas claramente informa o foco do PJ no desenvolvimento dos educatores-pares, mas, concomitantemente, parece haver certa sensação de abandono diante da fragilidade das ações de treinamento formais recebidas, bem como do fato de que não foi homogêneo o discurso quanto ao apoio recebido por parte dos técnicos supervisores do PJ em cada um dos serviços. Pode-se notar que tal abandono sobrecarrega os jovens tanto pela magnitude das finalidades propostas por eles ao seu trabalho, quanto pela ausência de integração com a equipe para dividir as responsabilidades sobre as ações desenvolvidas.

\section{Relação com a equipe do CTA}

Não foi identificada percepção de integração intraequipe, considerando-se o trabalho dos jovens plantonistas, mas justaposição de suas ações aos trabalhos realizados pelos demais profissionais nas unidades, tal como notado por Peduzzi em seu trabalho sobre equipes multidisciplinares de saúde (1998).

A integração entre diferentes agentes, atuando na prevenção das DST/Aids, no serviço de saúde poderia representar um grande acréscimo ao trabalho, tal como notado por Ebreo e col. (2002) num projeto de prevenção das DST/Aids desenvolvido em ambiente escolar. 0 projeto referido envolvia a atuação de jovens educadores de pares para trabalho conjunto com professores no desenvolvimento de ações de prevenção das DST/Aids no âmbito escolar. Estes autores observaram que a simples informação quanto à existência do trabalho dos jovens para os professores, não 
foi suficiente para o desenvolvimento de trabalho conjunto. A partir desta experiência, Ebreo e col. indicam a necessidade de desenvolvimento de atividades de treinamento que reúnam os jovens educadores de pares e os técnicos com os quais trabalharão de forma a promover adequada integração e definição mais clara sobre o envolvimento mútuo para que ambas as partes possam sentir-se confortáveis e confiantes quanto ao trabalho conjunto.

\section{Ações}

Ao caracterizarem as ações desenvolvidas no âmbito do PJ, os agentes jovens de prevenção enfatizam dois aspectos muito freqüentes na literatura especializada sobre educação entre pares: 1. a abertura do diálogo em função da paridade experimentada em referência à identidade geracional e à convivência no espaço comunitário comum; 2. a oposição ao papel do técnico expert, detentor de conhecimento técnico-científico que nega o saber prático do usuário em contraposição ao plantonista, detentor do mesmo saber leigo, dos códigos culturais e lingüísticos dos jovens e aberto, portanto ao diálogo entre saber técnico e saber leigo (Shiner, 1999; Ebreo e col., 2002; Ayres e col., 2003).

Apesar do reconhecimento de que há jovens com necessidades distintas, o acolhimento oferecido pelos plantonistas nas atividades individuais e coletivas é aquele em que essa identidade de par é afirmada, contrapondo-se ao acolhimento possível de ser realizado pelos técnicos e adultos.

Tendo em vista a atração vivida pelos plantonistas quanto às informações de caráter técnico-científico e a tendência, observada na descrição dos grupos educativos, de articulação entre uma "proposta de educação dialogada”, tal como descrita por Paiva (2002), mas pontuada por táticas de "medo", identificamos, como já havia sido discutido anteriormente por Ayres e col. (2003), que um desafio experimentado nas práticas de educação entre pares se dá na tensão observada entre os modelos de transmissão unilateral da informação e uma pedagogia mais construtivista, baseada na discussão entre os pares. Entendemos, como Ayres (2003) que tal tensão está relacionada à valorização social das informações técnico-científicas e que tal tensão precise ser explicitada e trabalhada nos processos de formação dos jovens educadores de pares.

\section{Impacto do trabalho sobre a imagem dos jovens plantonistas}

O trabalho desenvolvido no âmbito do PJ impacta a forma como os jovens plantonistas são vistos em suas comunidades e grupos de amigos, particularmente o desenvolvimento de ações fora do setting do CTA. Observamos na descrição deste impacto em suas vidas, a expressão de uma confusão entre identidade pessoal e profissional que revela um paradoxo da proposta de educação entre pares, dado que é por suas características pessoais que podem tornar-se educadores de pares, ou seja, profissionais.

\section{Finalidades do trabalho}

Ao mesmo tempo em que a visibilidade conferida pela experiência no PJ pesa quando se refere à sua identidade pessoal, os jovens valorizam em sua atuação profissional a possibilidade de se constituírem em referência e modelo de comportamento para os seus pares. Expressam o desejo e o reconhecimento de que sua inserção profissional possa servir como contraponto ao modelo de identificação que acreditam ser o vigente para seus pares, o do binômio droga/crime e, neste sentido, manifestam crítica em relação às perspectivas que identificam como presentes para outros jovens, como eles, no contexto suburbano. Entendem que a sua própria existência como agentes jovens de prevenção estimula a reflexão sobre as transformações possíveis nesta realidade e afirmam, entre as finalidades do seu trabalho, o seu papel como multiplicadores de valores entre os jovens. Por isso, apesar do impacto negativo sentido, compreendem ter responsabilidade na forma de se comportar, para não influenciar negativamente os pares. Neste exercício de se tornarem referências, refletem criticamente sobre quais valores, comportamentos e atitudes gostariam que fossem reproduzidos pelos jovens, quais as imagens de si que gostariam de transmitir. Definem-nas pela negação daquilo que julgam ser o estereótipo do jovem da periferia (ligado às drogas e à criminalidade) e pela afirmação da centralidade do trabalho na vida dos jovens brasileiros na atualidade, como já identificado em outros estudos sobre a juventude brasileira contemporânea (Projeto Juventude, 2004; Abramo, 2005; Abramo e Branco, 2005; Branco, 2005; Guimarães, 2005). Faz-se necessário, no entanto, aprofundar a discussão sobre os significados deste trabalho de- 
senvolvido no âmbito da transformação de valores sócio-culturais acerca da sexualidade.

\section{Considerações Finais}

A estratégia de educação entre pares rompe com a estratégia de prevenção tradicional em DST/AIDS (Paiva, 2002) ao estimular as práticas educativas entre agentes e usuários com compartilhamento de linguagens e experiências a partir da vivência de fase similar e posição social semelhante. Estratégia que se mostra bem sucedida, mas que mereceria ser re-estruturada a partir do saber construído pelos jovens no contexto relacional do seu cotidiano de trabalho, pois tal como afirma Schraiber (1999) este é "o saber que se origina do e no trabalho em seu cotidiano, com base na interação produzida pelas relações interpessoais da prática, pois será neste contexto relacional e de suas trocas intersubjetivas que conhecimentos científicos e tecnologias, além da experiência repassada ou pessoalmente vivida, serão combinados pelo profissional no exercício de sua profissão”. Destacamos a necessidade de aprofundar a discussão conceitual sobre educação entre pares incorporando as experiências dos jovens agentes de prevenção quanto aos dilemas pessoais experimentados no âmbito de seu trabalho no Plantão Jovem, em particular:

- a tensão relacionada à valorização da informação técnico-científica e a compreensão da centralidade do encontro e do diálogo;

- a confusão experimentada entre identidade pessoal e profissional que revela o paradoxo da proposta de educação entre pares, dado que é por suas características pessoais que podem tornar-se educadores de pares, ou seja, profissionais;

- a confusão entre os sujeitos agentes e a tecnologia operacionalizada, na dimensão da prática assistencial, já que vêem como competência estrutural do seu trabalho a capacidade de interação e comunicação com seus pares.

\section{Recomendações}

Em acordo com a literatura nacional e internacional que discute a educação entre pares, sugerimos que a adoção da referida estratégia, no âmbito do desenvolvimento de políticas públicas de saúde para adoles- centes e jovens explicite os modelos teóricos adotados e assegure suporte aos educadores de pares, por meio de treinamento e supervisão (Walker e Avis, 1999; Shiner, 1999).

No contexto brasileiro, sugerimos que gestores de políticas públicas explorem as possibilidades da lei de aprendizagem ao considerarem a incorporação de adolescentes e jovens na prestação de serviços em saúde como educadores de e prestadores de serviços para seus pares, tendo em vista a centralidade do trabalho na experiência juvenil contemporânea.

\section{Referências}

ABRAMO, H. W. Condição juvenil no Brasil contemporâneo. In: ABRAMO, H. W; BRANCO, P. P. (Org.). Retratos da juventude brasileira: análises de uma pesquisa nacional. São Paulo: P. Abramo, 2005. p. 73-86.

ABRAMO, H. W.; BRANCO, P. P. Apresentação. In: ABRAMO, H. W.; BRANCO, P. P. (Org.). Retratos da juventude brasileira: análises de uma pesquisa nacional. São Paulo: P. Abramo, 2005. p. 9-22.

AYRES, J. R. C. M. e col. Adolescência e aids: avaliação de uma experiência de educação preventiva entre pares. Interface, Botucatu, v. 7, n. 12, p. 113-128, 2003.

BACKETT-MILBURN, K.; WILSON, S. Understanding peer education: insights from a process evaluation. Health Education Research, Washington, DC, v. 15, n.1, p. 85-96, 2000 .

BARDIN, L. Análise de conteúdo. Lisboa: Ed. 70, 1977.

BERCOVICH, A.; MADEIRA, F. R.; TORRES, H. G. Descontinuidades demográficas. In: FUNCAÇÃO SEADE. Vinte anos no ano 20oo: estudos sociodemográficos sobre a juventude paulista. São Paulo, 1998. p. 2-12

BRANCO, P. P. Juventude e Trabalho: desafios e perspectivas para as políticas públicas. In: ABRAMO, H. W.; BRANCO, P. P. (Org.). Retratos da juventude brasileira: análises de uma pesquisa nacional. São Paulo: P. Abramo, 2005. p. 129-148.

EBREO, A. e col. Effects of peer education on the peer educators in a school-based HIV prevention program: where should peer education research go from here? Health Education \& Behavior, Thousand Oaks, CA, v. 29, n. 4, p. 411-423, Aug. 2002. 
GUIMARÃES, N. A. Trabalho: uma categoria-chave no imaginário juvenil? In: ABRAMO, H. W.; BRANCO, P. P. (Org.). Retratos da juventude brasileira: análises de uma pesquisa nacional. São Paulo: P. Abramo, 2005. p. $149-174$.

Instituto Cidadania. Projeto Juventude (Documento de conclusão - versão final). São Paulo, 2004. 98 p.

MENDES-GONÇALVES, R. B. Medicina e história: raízes sociais do trabalho médico. 1979. Dissertação (Mestrado em Medicina Preventiva) - Faculdade de Medicina, Universidade de São Paulo, São Paulo, 1979.

MENDES VIEIRA, R. Comunicação pessoal (Coordenadora dos Plantões Jovens no âmbito da Área Técnica de DST/Aids da Secretaria Municipal da Saúde à época da realização da pesquisa), em 22 de setembro de 2004.

MESQUITA, F. DST/AIDS: a nova cara da luta contra a epidemia na cidade de São Paulo [ETS/SIDA: la nueva cara de la lucha contra la epidemia en la ciudad de São Paulo]. MESQUITA, F. E SOUZA, C. R. de (Org.). São Paulo: Editora Raiz da Terra, 2003.

MINAYO, M. C. de S. O desafio do conhecimento: pesquisa qualitativa em saúde. São Paulo: Hucitec; Rio de Janeiro: Abrasco, 1996. 269 p.

PAIVA, V. Sem mágicas soluções: a prevenção e o cuidado em HIV/AIDS e o processo de emancipação psicossocial. In: Interface, Botucatu, v. 6, n. 11, p. 25-38, ago. 2002.

PEDUZZI, M. Equipe multiprofissional de saúde: a interface entre trabalho e interação. 1998. Tese (Doutorado em Saúde Coletiva) - Faculdade de Ciências Médicas, Universidade Estadual de Campinas, Campinas, 1998.
PMSP - PREFEITURA DO MUNICÍPIO DE SÃO PAULO. Sumário de dados do município de São Paulo 2004. Disponível em: <http://portal.prefeitura.sp.gov.br/secretarias/governo/sumario_dados/oooz>. Acesso em: 26 mar. 2006.

POPE, C.; MAYS, N. Pesquisa qualitativa na atenção à saúde. Porto Alegre: Artmed, 2005.

RODRIGUES, E. M. et al. Distribuição espacial. In: FUNCAÇÃO SEADE. Vinte anos no ano 20oo: estudos sociodemográficos sobre a juventude paulista. São Paulo, 1998. p. 14-33.

SCHRAIBER, L. Medicina tecnológica e prática profissional contemporânea: novos desafios, outros dilemas. 1997. Tese (Livre-docência em Medicina Preventiva) Faculdade de Medicina, Universidade de São Paulo, São Paulo, 1997.

SCHRAIBER, L. Planejamento, gestão e avaliação em saúde: identificando problemas. Ciência \& Saúde Coletiva, Rio de Janeiro, v. 4, n. 2, p. 221-242, 1999.

SHINER, M. Defining peer education. Journal of Adolescence, London, v. 22, n. 4, p. 555-566, 1999.

WALKER, S. A.; AVIS, M. Common reasons why peer education fails. Journal of Adolescence, London, v.22, n. 4, p. 573-577, 1999

WREN, P. A. e col. Preventing the spread of Aids in youth: principles of practice from 11 diverse projects. Journal of Adolescent Health, New York, NY, v. 21, n. 5 , p. 309-317, 1997 